\title{
Optimal design of the oxidizer nozzles of a coal gasifier using the CFD method
}

\author{
C. Lee ${ }^{1}$, N. Y. Lee ${ }^{1}$, S. J. Lee ${ }^{2} \&$ J. W. Lee ${ }^{2}$ \\ ${ }^{1}$ Department of Mechanical Engineering, University of Suwon, Korea \\ ${ }^{2}$ Plant Engineering Center, Institute for Advanced Engineering, Korea
}

\begin{abstract}
The present study optimizes the oxidizer feed nozzles of a coal gasifier by using a computational fluid dynamics (CFD) technique. The CFD model on coal gasification is constructed by combining Reynolds stress averaged NavierStokes equation solver, turbulence, discrete phase and gasification reaction kinetic models. With the changes of nozzle size and oxidizer feed distribution of the coal gasifier, coal gasification performances are calculated by the present CFD method. From the CFD calculation results, the optimal design conditions of oxidizer nozzles can be obtained to maximize carbon conversion and cold gas efficiency by up to $97 \%$ and $82 \%$ respectively.
\end{abstract}

Keywords: CFD, coal gasification, cold gas efficiency, carbon conversion, oxidizer nozzle, optimal design.

\section{Introduction}

Coal gasification is one of the clean coal techniques, which converts solid fuel to syngas fuel, so it is widely used in the integrated gasification combined cycle (IGCC), synthetic natural gas (SNG) and other chemical plants [1]. For this reason, worldwide R\&D efforts for efficient coal gasification are being attempted in the USA, Europe, Japan and also in Korea. The main objectives of coal gasification research has focused on how to convert coal energy into syngas energy as much as possible through the design of a coal gasifier. Because coal and oxidizer feed conditions severely affect coal gasification efficiency, many previous coal gasification research investigated various nozzle designs with axial, swirling, opposing or staged flow types [2-5]. In Korea, a new coal gasifier has 
been developed through the test-bed facility of a 300MW IGCC power plant since 2010.

The present study, as part of the Korean IGCC project, conducts computational analyses on the test-bed coal gasifier in order to optimize oxidizer nozzle design. Present CFD modeling is made by combining a Reynolds-stress averaged Navier-Stokes equation solver, turbulence, discrete phase and gasification reaction kinetic models. The present CFD simulation method calculates the gas flow path, the coal particle track, the temperature, the $\mathrm{CO}$ and $\mathrm{H}_{2}$ distributions inside the gasifier. Furthermore, the calculation results are used to investigate and compare the gasifier performances such as cold gas efficiency and carbon conversion when the nozzle design is changed.

\section{Coal gasifier design}

\subsection{Design concept and specifications of the coal gasifier}

The present study employs the bituminous coal of the following proximate analysis results as $6 \%$ moisture, 51\% fixed carbon, $28 \%$ volatile and $15 \%$ ash. The design operating conditions of coal gasification are set to $20 \mathrm{~atm}(\mathrm{~g})$ and $1400^{\circ} \mathrm{C}$.

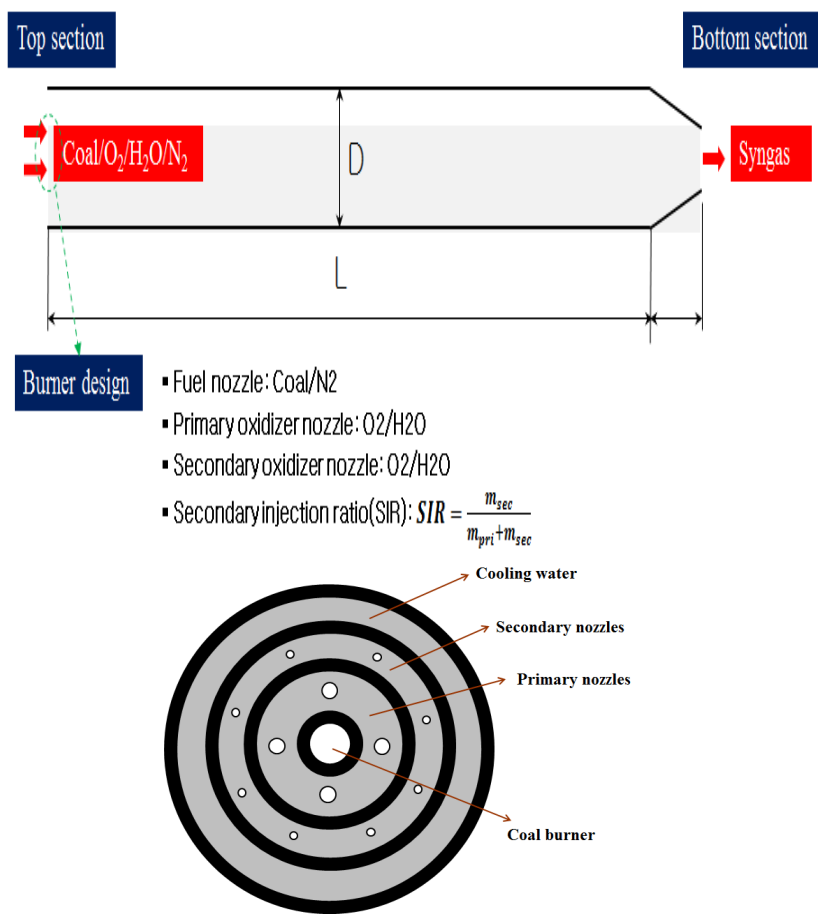

Figure 1: Coal gasifer design concept. 
As shown in Fig. 1, the present coal gasifier is designed as an entrained-bed type with the aspect ratio (L/D) of 6 , and co-axial coal burner, primary and secondary oxidizer nozzles are equipped on the top plane of the gasifier. The feed conditions of the gasifier are 20 ton/day of coal, 15 ton/day of oxygen, 2 ton/day of steam and 3 ton/day of nitrogen. It is noted that oxygen and steam are mixed and then fed into the gasifier as the oxidizer of coal through primary and secondary nozzles while nitrogen is being fed as coal-transport gas through a coal burner. One coal burner is equipped at the center of the top plane, and four primary and eight secondary nozzles are located around the inner and outer peripherals of the coal burner. In order to investigate the effect of oxidizer nozzle design on coal gasification performance, the present study considers two design variables, primary nozzle size $\left(D_{p}\right)$ and secondary injection ratio (SIR). Here SIR is defined as the oxidizer feed rate through secondary nozzles divided by the total oxidizer one.

\subsection{CFD models and analysis method}

The numerical modeling and simulation by a CFD method are made to optimize oxidizer nozzle design for maximizing gasifier efficiency. As summarized in Fig. 2, the present CFD model is based on the Reynolds-stress Averaged Navier Stokes equations (RANS) solvers coupled with realizable k- $\varepsilon$ turbulence, discrete-phase models and chemical kinetic models for gas phase and char surface gasification reactions. The discrete phase model are based on the iterative computations for the Eulerian and the Lagrangian approaches for gas and coalsolid flows, and employs the Random walk model for considering the coal particle dispersion by turbulence [6].

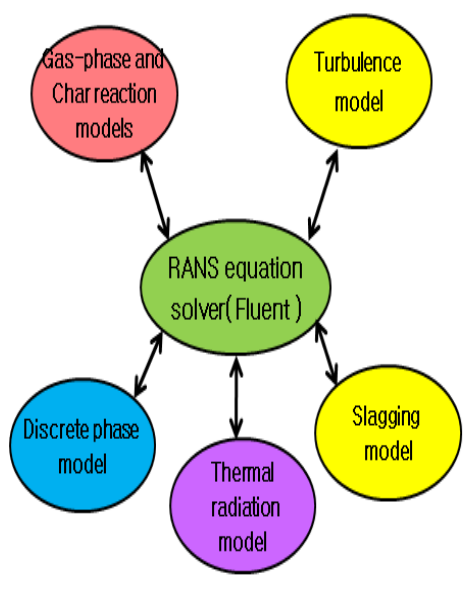

\begin{tabular}{|c|l|}
\hline $\begin{array}{c}\text { Physical/ } \\
\text { Chemical } \\
\text { Phenomena }\end{array}$ & \multicolumn{1}{|c|}{ CFD numerical model } \\
\hline $\begin{array}{c}3-D \\
\text { flow/energy } \\
\text { transport }\end{array}$ & $\begin{array}{l}\text { Reynolds-stress Averaged } \\
\text { Navier-Stokes(RANS) equation } \\
\text { solver }\end{array}$ \\
\hline $\begin{array}{c}\text { Turbulence } \\
\text { Realizablek- } \varepsilon \text { turbulence } \\
\text { model with wall function }\end{array}$ \\
\hline $\begin{array}{c}\text { Gasification } \\
\text { reactions }\end{array}$ & $\begin{array}{l}\text {-Gas-phase(homogeneous) } \\
\text { and Char(heterogeneous) } \\
\text { reaction kinetics models }\end{array}$ \\
\hline $\begin{array}{c}\text { Coal } \\
\text { particle } \\
\text { track }\end{array}$ & $\begin{array}{l}\text { Discrete phase trajectory model } \\
\text { with turbulence-solid particle } \\
\text { interaction( random walk model) }\end{array}$ \\
\hline $\begin{array}{c}\text { Thermal } \\
\text { radiation }\end{array}$ & $\begin{array}{l}\text { P1 thermal radiation model for } \\
\text { gas and solid media }\end{array}$ \\
\hline
\end{tabular}

Figure 2: The present CFD models and analysis method. 
For modeling coal gasification reactions, the present study assumes that coal is decomposed into volatile and char. The volatile production from coal is modeled by two competing-rate mechanism by Kobayashi et al. [7], and produced volatile is assumed to take the following gas phase reactions:

$$
\begin{gathered}
\text { Volatile } \rightarrow 0.56 \mathrm{CO}+0.625 \mathrm{H}_{2}+0.8 \mathrm{CH}_{4} \\
\text { Volatile }+2.192 \mathrm{O}_{2} \rightarrow 1.35 \mathrm{CO}_{2}+2.25 \mathrm{H}_{2} \mathrm{O} \\
\mathrm{CH}_{4}+0.5 \mathrm{O}_{2} \rightarrow \mathrm{CO}+2 \mathrm{H}_{2} \\
\mathrm{H}_{2}+0.5 \mathrm{O}_{2} \rightarrow \mathrm{H}_{2} \mathrm{O} \\
\mathrm{CO}+0.5 \mathrm{O}_{2} \rightarrow \mathrm{CO}_{2} \\
\mathrm{CH}_{4}+\mathrm{H}_{2} \mathrm{O} \leftrightarrow \mathrm{CO}+3 \mathrm{H}_{2} \\
\mathrm{CO}+\mathrm{H}_{2} \mathrm{O} \leftrightarrow \mathrm{CO}+\mathrm{H}_{2}
\end{gathered}
$$

In addition, char surface reactions are modeled by the apparent rate/diffusion rate model for three kinds of char reactions as follows:

$$
\begin{gathered}
\mathrm{C}(\mathrm{s})+0.5 \mathrm{O}_{2} \rightarrow \mathrm{CO} \\
\mathrm{C}(\mathrm{s})+\mathrm{CO}_{2} \rightarrow 2 \mathrm{CO} \\
\mathrm{C}(\mathrm{s})+\mathrm{H}_{2} \mathrm{O} \rightarrow \mathrm{CO}+\mathrm{H}_{2}
\end{gathered}
$$

Here all the kinetic parameters of the equations (1)-(10), pre-exponential factor, activation energy and temperature exponent, are referred to in Watanabe and Otaka [4].

\section{Computational results and discussions}

The present study conducts the numerical analyses on the design cases of a coal gasifier when $D_{p}$ and SIR are changed. $D_{p}$ is increased or decreased by a maximum of $1 \mathrm{~mm}$ from reference size $\left(\mathrm{D}_{\mathrm{p}, \mathrm{ref}}\right)$, while SIR is increased from 0 to $100 \%$. It is noted that because the changes of $D_{p}$ and SIR result in the variations of the gas momenta of oxidizer mixtures through primary and secondary nozzles, so these momentum variations can cause different mixing patterns between coal and oxidizer, which are mainly determined by the momentum differences of coal burner, primary and secondary nozzles [8].

For better understanding on the gas momentum design concept of the present study, the gas momenta of coal burner, primary and secondary nozzles are compared in Fig. 3 at varied $D_{p}$ and SIR. As shown in Fig. 3, there are big gas momentum differences between coal burner, primary and secondary nozzles at SIR $=0$ or $100 \%$, which can result in rapid mixing of coal and oxidizer as well as the gas recirculation region below the top plane of the gasifier. However, as shown also in Fig. 3 when SIR is set to $50 \%$, the gas momenta of the coal burner, primary and secondary nozzles are more equally distributed and then is expected to give a slower mixing of coal and oxidizer along the gasifier length than the cases when SIR is set to 0 or $100 \%$. 


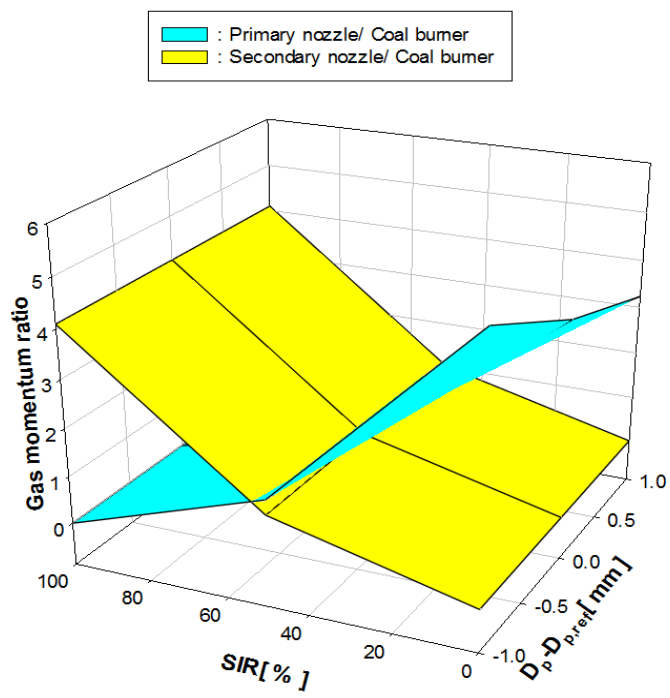

Figure 3: Gas momenta of the coal burner and oxidizer nozzles.

\subsection{Local reacting flow fields of coal gasifier}

The CFD results on gas velocity, species composition and temperature distributions are compared for three design cases when SIR is changed but $D_{p}$ is fixed as $\mathrm{D}_{\text {p,ref. }}$ Fig. 4 shows the gas streamlines and velocity vector of a coal gasifier for three SIR cases, which illustrate the gas recirculation region below the top plane due to the mixing of coal and oxidizer. Comparing the lengths of the gas recirculation regions of the three cases, the recirculation region of the case at $\mathrm{SIR}=50 \%$ is shorter than the other cases. From the calculation results on gas recirculation regions, it is known that the equally-distributed gas momentum design at $\mathrm{SIR}=50 \%$ is more suitable for uniform mixing and coal gasification reaction than other cases at $\mathrm{SIR}=0$ or $100 \%$.

Fig. 5 shows the coal particle concentrations inside the gasifier. As expected from the results of Fig. 4, when SIR is set to $50 \%$, coal particles are more uniformly dispersed and then are expected to be mixed and reacted with the oxidizer under a more proper gasification condition.

Fig. 6 shows the temperature distributions inside the gasifier with changing $\mathrm{SIR}$, and also represents more uniform temperature distribution at $\mathrm{SIR}=50 \%$ than those at SIR $=0$ or $100 \%$. From these temperature computation results, it is known that the slow mixing between coal and oxidizer in the case of SIR $=50 \%$ is more preferable for maintaining proper and uniform gasification temperature over the total gasifier region than the other SIR conditions. Furthermore, the higher temperature regions in the cases of SIR $=0$ or $100 \%$ might trigger the combustion mode of coal, producing more $\mathrm{CO}_{2}$.

Figs 7 and 8 depict the distributions of $\mathrm{CO}$ and $\mathrm{H}_{2}$ mass fractions inside the gasifier. Fig. 7 shows the case of SIR $=50 \%$ results in more enhanced $\mathrm{CO}$ 


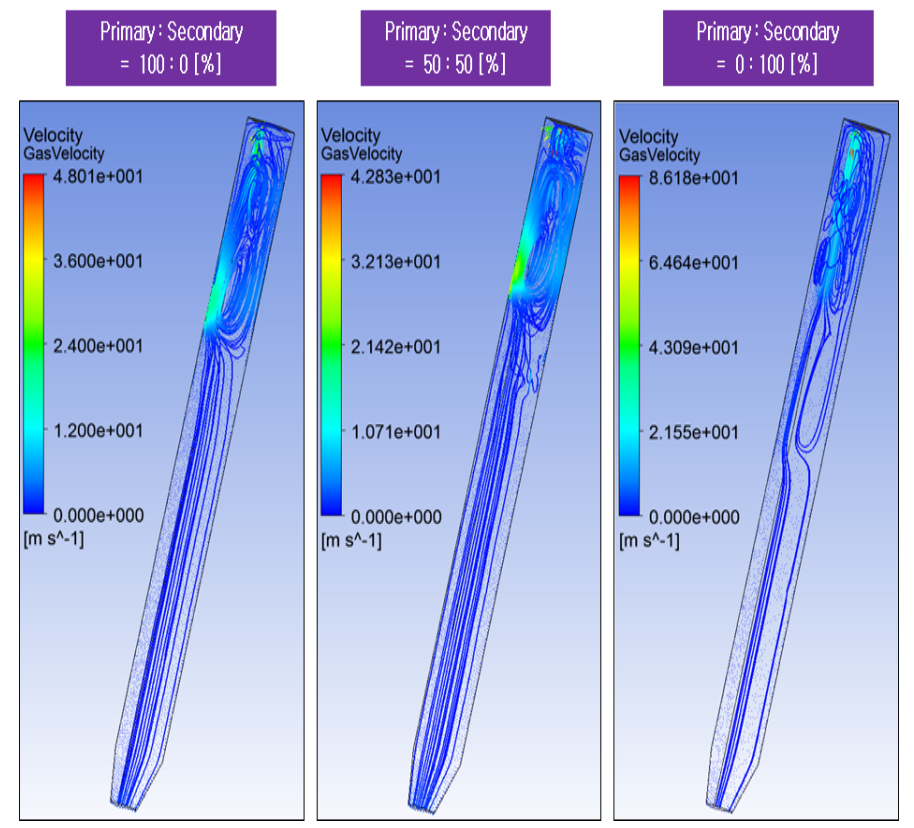

Figure 4: Streamlines and velocity vector of the coal gasifier.
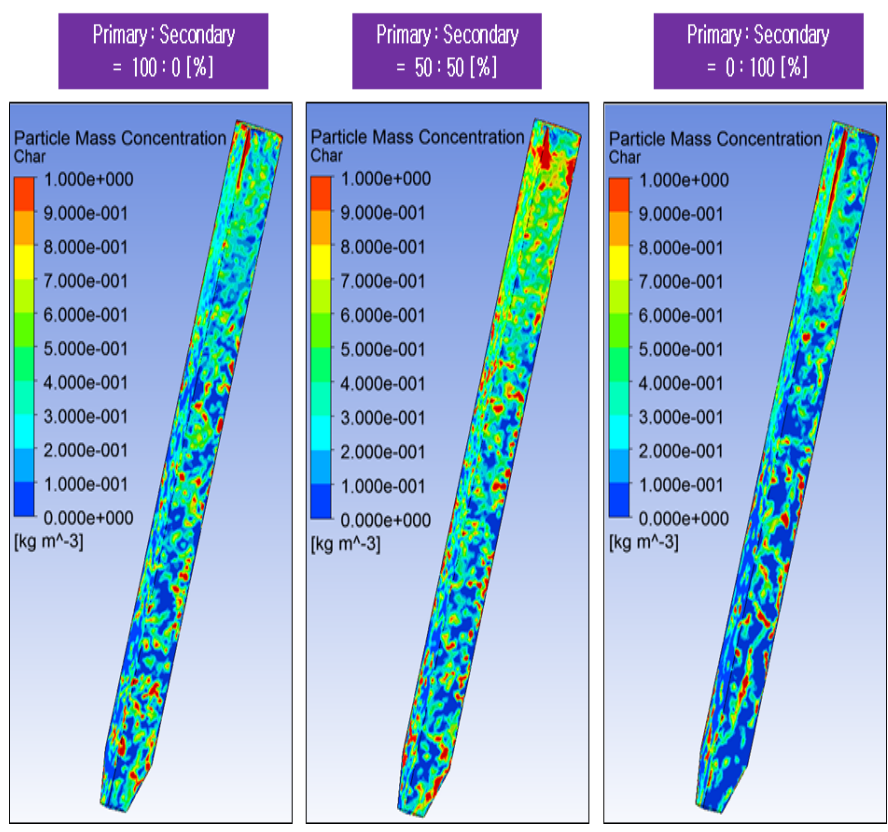

Figure 5: Coal particle concentration of the coal gasifier. 


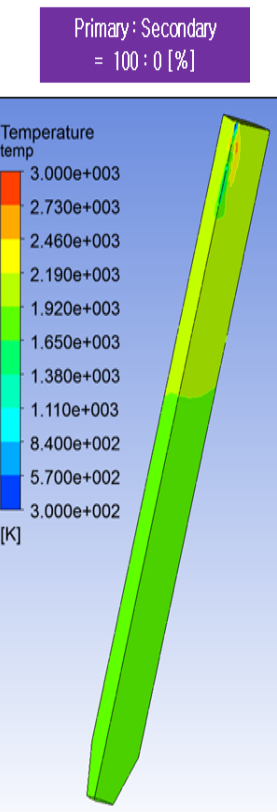

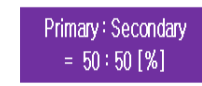
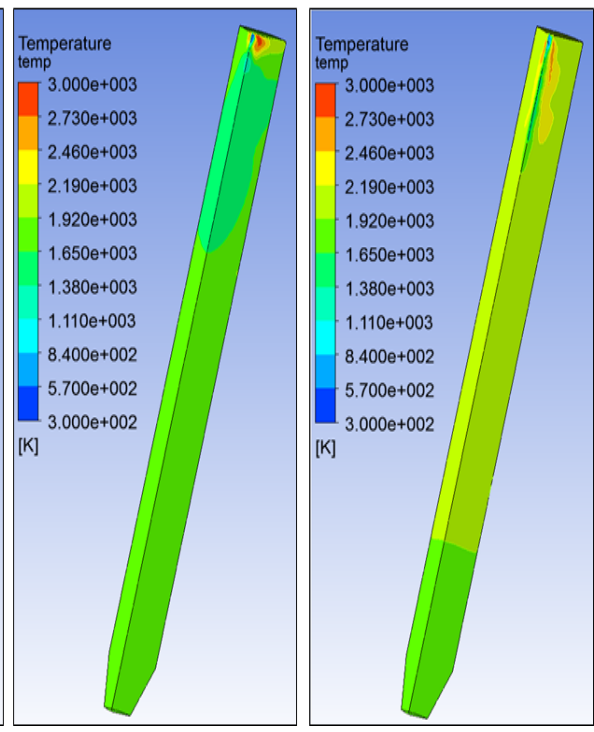

Figure 6: Temperature distributions of the coal gasifier.
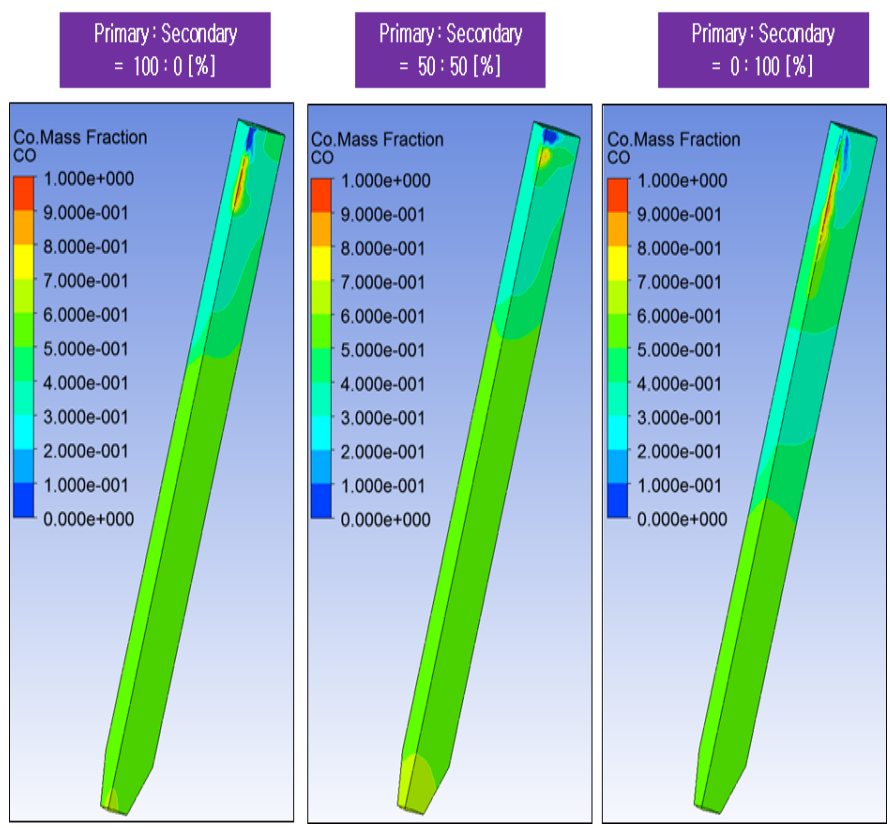

Figure 7: $\quad \mathrm{CO}$ mass fraction distributions of the coal gasifier. 


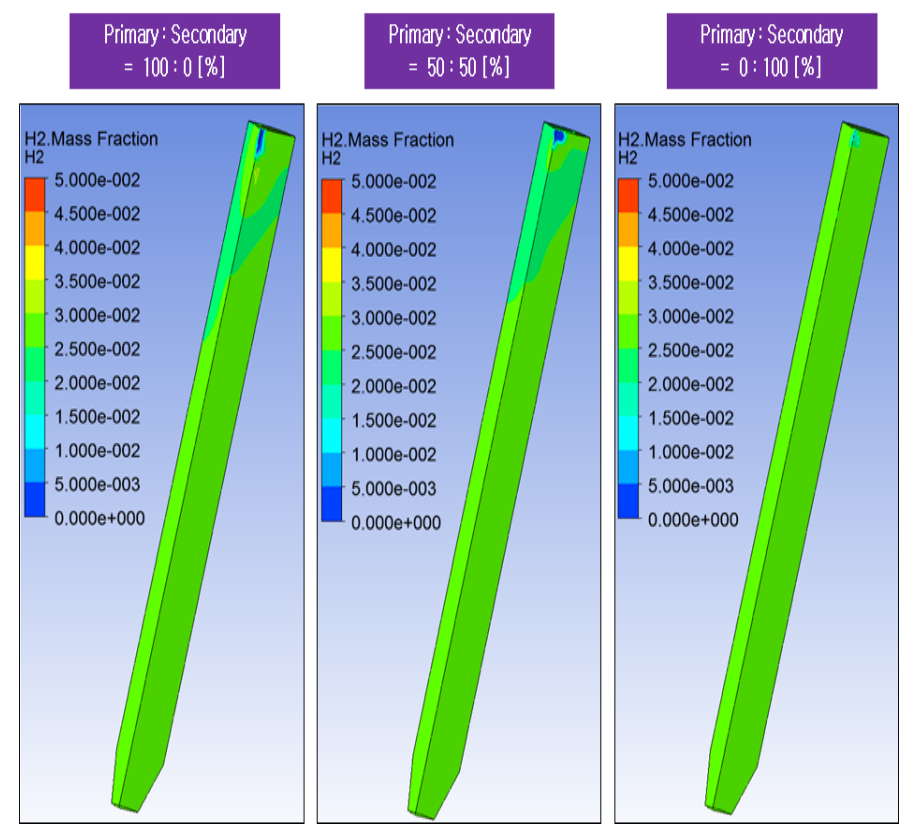

Figure 8: $\mathrm{H}_{2}$ mass fraction distribution of the coal gasifier.

production around a coal burner than other cases because of its uniform temperature distribution suitable for gasification reaction. However, Fig. 8 shows that $\mathrm{H}_{2}$ production is dispersed along the gasifier length at any SIR condition. Because $\mathrm{H}_{2}$ production should be obtained through the series of reactions of coal and volatile decompositions (refer to equations (1) and (2)), so it generally takes more time and a longer distance to produce $\mathrm{H}_{2}$ than the $\mathrm{CO}$.

\subsection{Overall performances of a coal gasifier}

The present study examines the syngas composition and temperature at the gasifier exit and also determines the overall gasification performances such as cold gas efficiency and carbon conversion.

Figs 9 and 10 show the gas composition of $\mathrm{CO}$ and $\mathrm{H}_{2}$ at the gasifier exit. As shown in Figs 9 and 10, when $\mathrm{D}_{\mathrm{p}}$ is increased or decreased from reference size, $\mathrm{CO}$ composition is increased by up to a maximum of $62 \%$ but $\mathrm{H}_{2}$ composition is reduced down to $23 \%$. However, in spite of changing SIR, the compositions of $\mathrm{CO}$ and $\mathrm{H}_{2}$ remain as almost constant values of $46 \%$ and $30 \%$ at the reference nozzle size $\left(\mathrm{D}_{\mathrm{p}, \mathrm{ref}}\right)$. 


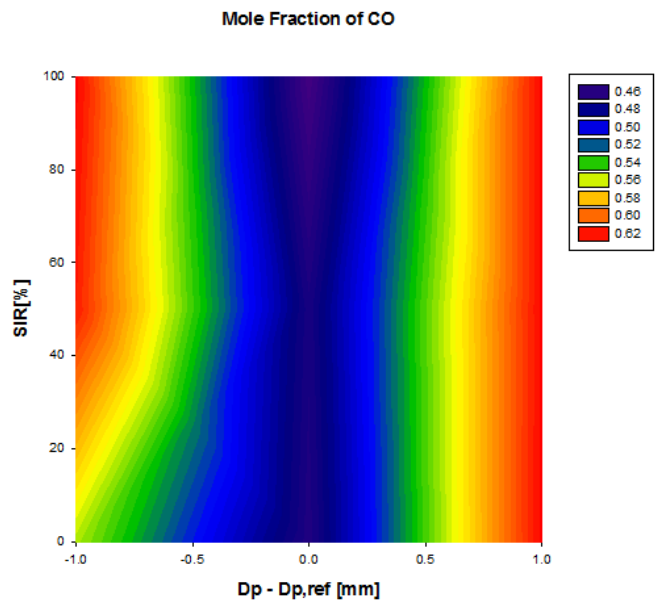

Figure 9: $\mathrm{CO}$ composition at the coal gasifier exit.

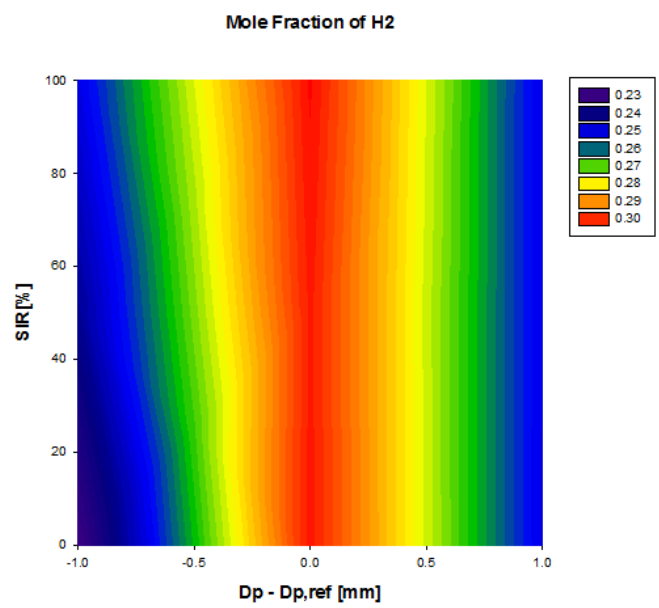

Figure 10: $\mathrm{H}_{2}$ composition at the coal gasifier exit.

Fig. 11 shows the syngas temperature at the gasifier exit, which remarkably changes from 1700 to $1850 \mathrm{~K}$ when $\mathrm{Dp}$ and SIR are varied. These temperature variations can be explained by that, with changing SIR and Dp, the mixing pattern of coal and oxidizer is significantly varied as examined before in Fig. 5 and then it may cause coal combustion on the part of the coal gasifier reactor, producing a higher temperature. However, as shown also in Fig. 11, the lowest but the most suitable gasification temperature is found when SIR $=50 \%$ and $\mathrm{Dp}=$ Dp,ref. 


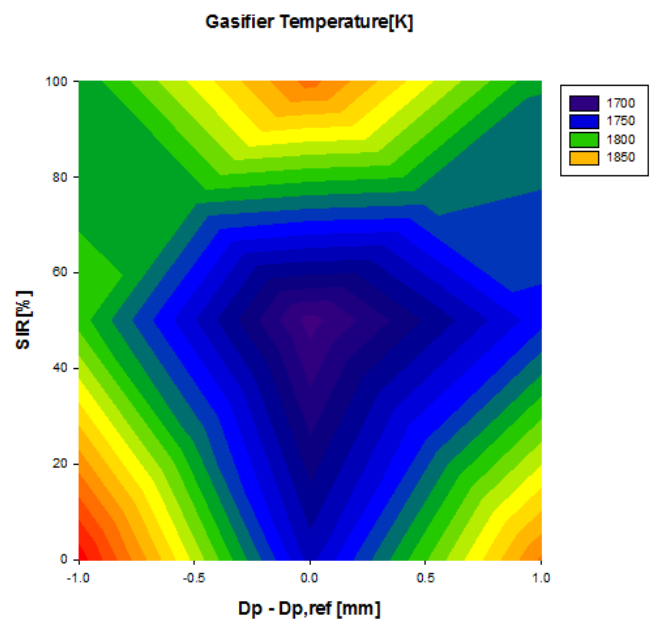

Figure 11: Syngas temperature at the coal gasifier exit.

Figs 12 and 13 represent overall coal gasification performances, the cold gas efficiency and the carbon conversion of the gasifier, which have the highest values of $82.2 \%$ and $97.3 \%$ when SIR $=50 \%$ and $\mathrm{Dp}=\mathrm{Dp}$,ref. These analysis results correspond to the local reacting flow field, the syngas composition and temperature calculation results of Figs 4-11, and furthermore imply that the coal/oxidizer nozzles of the gasifier are very important and should be optimized to maximize coal gasification efficiency.

Cold Gas Efficiency[\%]

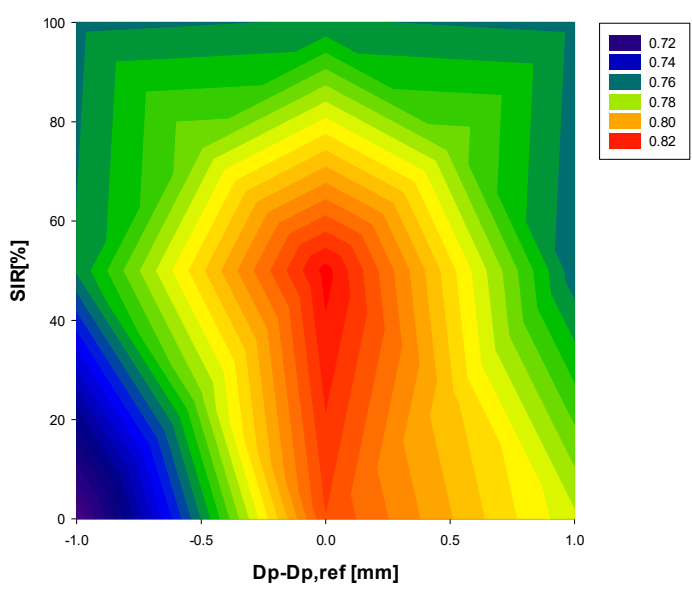

Figure 12: Cold gas efficiency of the gasifier. 


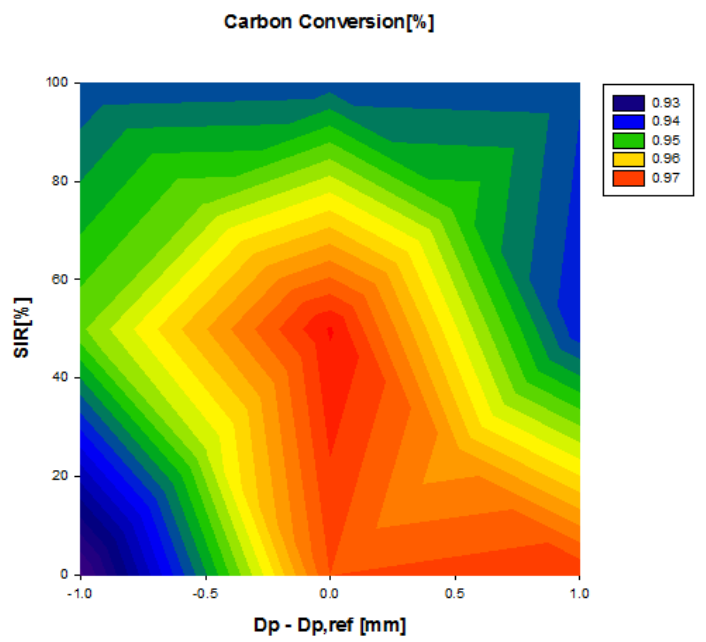

Figure 13: Carbon conversion of the gasifier.

\section{Conclusions}

Computational analyses by CFD code are conducted to optimize the design conditions for the coal burner, oxidizer primary and secondary nozzles of a Korean test-bed coal gasifier. In the present study, CFD simulations on the reacting flow filed inside the gasifier are made with changing oxidizer nozzle design parameters, secondary injection ratio (SIR) and primary nozzle size (Dp). The simulation results show that the nozzle design with $\mathrm{SIR}=50 \%$ and $\mathrm{Dp}=$ $\mathrm{Dp}$,ref is the most preferable for uniform coal/oxidizer mixing and efficient coal gasification reaction. The coal gasifier with the optimum nozzle design also shows the best coal conversion and cold gas efficiency as $97 \%$ and $82 \%$.

\section{Acknowledgements}

This work was supported by the New and Renewable Energy Core Technology Program of the Korea Institute of Energy Technology Evaluation and Planning (KETEP) granted financial resource from the Ministry of Trade, Industry and Energy, Republic of Korea (No. 2011951010001C).

\section{References}

[1] Minchener, A. J., "Coal gasification for advanced power generation", Fuel, 84, pp. 2222-2235, 2005

[2] Niksa, S., Liu, G. and Hurt, R. H., "Coal conversion submodels for design applications at elevated pressures. Part I. devolatilization and char oxidation," Progress in Energy and Combustion Science, 29, pp. 425-477, 2003 
[3] Song, J., Kang, M., Seo, D., Lim, S., Paek M. and Hwang, J., "CFD Modeling for 300MW Shell-Type One-Stage Entrained Flow Coal Gasifier : Effect of O2/Steam/Coal Ratios, Particle Sizes, and Inlet Angles on the Gasifier Performance" Trans. of the Korean Hydrogen and New Energy Society, 21(3), pp. 227-240, 2010

[4] Watanabe, H. and Otaka, M., "Numerical simulation of coal gasification in entrained flow coal gasifier", Fuel, 85, pp. 1935-1943, 2006

[5] Zitney, S. E. and Guenther, C., "Gasification CFD Modeling for Advanced Power Plant Simulations," NETL-TPR-1193, 2005

[6] Fluent 6.3 User Guide, Fluent Inc., 2006

[7] Kobayashi, H., Howard, J. B. and Sarofim. A. F., "Coal Devolatilization at High Temperatures," Int'l 16th Symp. on Combustion, The Combustion Institute, 1976

[8] Beer, J. M. and Chigier, N. A., Combustion Aerodynamics, John Wiley \& Sons Inc., New York, 1972 